\title{
Mechanical and Volumetric Fracturing Behaviour of Three-Dimensional Printing Rock-like Samples Under Dynamic Loading
}

\author{
Tao Zhou ${ }^{1,2} \cdot$ Jianbo Zhu ${ }^{1,3}$ (D) Heping Xie ${ }^{1}$
}

Received: 27 July 2018 / Accepted: 3 March 2020 / Published online: 14 March 2020

(c) The Author(s) 2020, corrected publication 2020

\begin{abstract}
Heterogeneous rock contains numerous pre-existing three-dimensional (3D) cracks, which control its mechanical and fracturing properties. Considerable effort has been devoted to studying the volumetric fracturing behaviour of rock under static loading conditions. Although rock masses are often subject to dynamic impacts such as earthquakes and blasting, the mechanical and volumetric fracturing behaviour of rock under dynamic loading is still poorly understood. In this paper, dynamic laboratory tests were performed on 3D-printed artificial rock samples with 3D embedded flaws created during three-dimensional printing (3DP), with the aim of studying the volumetric fracturing and mechanical properties of these samples under impact with high strain rate. The results show that the dynamic compressive strength and the tangent modulus decrease with an increasing number of flaws, but have very limited effects on the ratio of the fracture initiation stress of the first crack to the peak stress of the sample, the maximum axial strain of the sample and the volumetric fracturing behaviour of the sample. The tensile failure of a sample is caused by the continuous extension of wing cracks from the outer flaw tips. The mechanical and volumetric fracturing behaviour of samples with 3D embedded flaws are strain rate dependent. The tangential modulus and the ratio of the fracture initiation stress of the crack to the peak stress increase significantly when the loading type changes from static compression to dynamic compression. Under dynamic compression, wing cracks can continuously extend to the sample ends, whereas under static compression, wing cracks can intermittently extend only a limited distance. Moreover, the fracturing behaviour of 3D flaw differs from that of 2D flaws under dynamic loading. Under high strain rate loading, wing cracks generated at 3D flaw tips lead to splitting failure of the sample, while shear cracks formed at 2D flaw tips result predominant shear failure of the sample. The findings in this paper could facilitate a better understanding of rock failure subjected to dynamic loading conditions.
\end{abstract}

Keywords Volumetric fracturing $\cdot 3 \mathrm{D}$ embedded flaw $\cdot 3 \mathrm{D}$ printing $\cdot$ Wing crack $\cdot$ Dynamic loading

\section{Introduction}

Jianbo Zhu

jbzhu@tju.edu.cn

1 Guangdong Provincial Key Laboratory of Deep Earth Sciences and Geothermal Energy Exploitation and Utilization, Institute of Deep Earth Sciences and Green Energy, Shenzhen University, Shenzhen, China

2 Department of Civil and Environmental Engineering, The Hong Kong Polytechnic University, Kowloon, Hong Kong SAR

3 State Key Laboratory of Hydraulic Engineering Simulation and Safety, School of Civil Engineering, Tianjin University, Tianjin, China
Rock is heterogeneous and contains a multitude of preexisting micro- and macro-defects, e.g., voids, inclusions and joints. The collapse of rock materials subjected to external or internal loads is due to both the activation of these pre-existing defects and the generation of new micro- and macro-cracks (Peng and Johnson 1972). Thus, it is of great academic interest and engineering significance to understand volumetric fracturing behaviour in rock and rock masses. Volumetric fracturing refers to the three-dimensional (3D) fracturing process characterized by large-scale, multi-fracture, high-intensity damage and energy release, resulting from the interaction, growth, and division of the internal defects of the rock (Xie et al. 2016; Zhou et al. 2019). 
Rock heterogeneity makes it difficult to predict and analyse crack growth in rocks using theoretical methods (Liu et al. 2004). In contrast, as a fundamental and effective method, laboratory experiments enable scholars to directly monitor and study crack growth in rocks under various conditions. To date, a large number of experimental investigations have been performed to study two-dimensional (2D) crack initiation and coalescence in rocks subject to static loading (Bobet and Einstein 1998; Feng et al. 2009; Wong et al. 2001; Yang et al. 2009; Zhang et al. 2018). Wong and Einstein (2009) analysed crack initiation, propagation and coalescence in gypsum samples and marble samples each containing a single 2D flaw (henceforth defined as pre-existing defect) subject to static compression. They noted that the cracks that initiate from the pre-existing 2D flaws can be characterized into three main types, i.e., tensile cracks, shear cracks and mixed tensile-shear cracks. Gale et al. (2007) investigated the importance of natural pre-existing defects for hydraulic fracture treatment in enhanced geothermal systems and noted that even the smaller sealed defects serve as weak planes that significantly affect the propagation of the hydraulic fractures.

Rock is often subjected to dynamic loads such as earthquakes and blasting (Deng et al. 2015; Yim et al. 1980). 2D crack growth in rock and gypsum samples has been investigated under not only static loading conditions but also dynamic loading conditions in recent years ( $\mathrm{Li}$ et al. 2016, 2017; Li and Wong 2012; Zou and Wong 2014). Zou and Wong (2014) extended the research of cracking processes in rock samples with 2D flaws from static loading conditions to dynamic loading conditions. Li et al. (2017) performed experiments on plate samples with 2D flaws using a split Hopkinson pressure bar (SHPB) device. In these studies, shear cracks always occurred prior to tensile cracks in the SHPB tests, and the tensile cracks were often suppressed by the dominant propagation of shear cracks. Additionally, it was reported that the presence of $2 \mathrm{D}$ flaw may change the failure mode of marble from splitting-dominated to sheardominated failure under dynamic loading ( $\mathrm{Li}$ et al. 2017; Zou and Wong 2014).

Naturally, flaws in rock are 3D features. To date, many studies have been conducted to study the growth of 3D surface flaws (Adams and Sines 1978; Liang et al. 2012; Wong et al. 2004; Zhou et al. 2018a). A 3D surface flaw is a flaw that is partially embedded in rock (Yin et al. 2014). Cannon et al. (1990) performed static uniaxial compression experiments on polymethyl methacrylate (PMMA) samples containing a half-penny shaped 3D surface flaw. They reported that crack propagation from pre-existing 3D surface flaws differs from that in 2D flaws. Wing cracks were observed to form sail-like geometries, as they wrapped around the edges of 3D surface flaws. Yin et al. (2014) carried out an experimental study on granite samples fabricated with two
3D surface flaws under static compression with the aim of investigating the coalescence mechanism between the preexisting flaws. Two major coalescence mechanisms in the fracturing process of the 3D surface flaws were identified: the linkage between the surface flaws and the coalescence between the petal cracks within the rock.

In addition to 3D surface flaws, numerous 3D embedded flaws also exist in rock. However, studies on the volumetric fracturing behaviour of 3D embedded flaws are quite limited. One of the reasons for this limitation is the difficulty in producing samples containing 3D embedded flaws. By embedding a thin aluminium foil plate inside the model when preparing rock-like samples, Dyskin et al. (2003) prepared resin samples with 3D embedded flaws. After conducting static uniaxial compression tests on those resin samples, it was found that the wing cracks generated from the pre-existing 3D embedded flaws can propagate only a limited distance (Dyskin et al. 1994, 2003). Recently, Zhou et al. (2019) proposed using 3DP to repeatedly and precisely prepare resin samples with 3D embedded flaws. They investigated volumetric fracturing using 3D-printed artificial rock samples containing 3D embedded flaws under static loading conditions. By comparing the wing crack growth and failure pattern of 3DP resin samples each containing a single flaw with the inclination angle of $30^{\circ}$ with previous findings presented by Germanovich et al. (1994) and Dyskin et al. (2003) under similar loading conditions, Zhou et al. (2019) validated the application of flawed resin samples produced via 3DP to the investigation of crack propagation and coalescence under compression.

However, no study on volumetric fracturing of 3D embedded flaws under dynamic loading conditions has been reported so far. Therefore, it is necessary to study the volumetric fracturing and mechanical behaviour of rock or rocklike samples with 3D embedded flaws subjected to dynamic loading.

In this paper, dynamic tests were performed on artificial rock samples with 3D embedded flaws prepared using 3DP, with the aim of investigating volumetric fracturing and the mechanical behaviour of rock under dynamic compression. The influences of the loading type and number of flaws on the mechanical properties and volumetric fracturing behaviour were analysed. A comparison between the volumetric fracturing and mechanical behaviour of 3D embedded flaws under static and dynamic loading conditions and a comparison between the $2 \mathrm{D}$ and volumetric fracturing behaviour of 3D embedded flaws subjected to dynamic loading were performed. This study is a further study of the volumetric fracturing and mechanical properties of resin-based 3D-printed samples containing 3D embedded flaws under static compression (Zhou et al. 2019). The findings in this paper could facilitate a better understanding of the failure behaviour and mode of rock under dynamic loading conditions. Notably, 
(a)

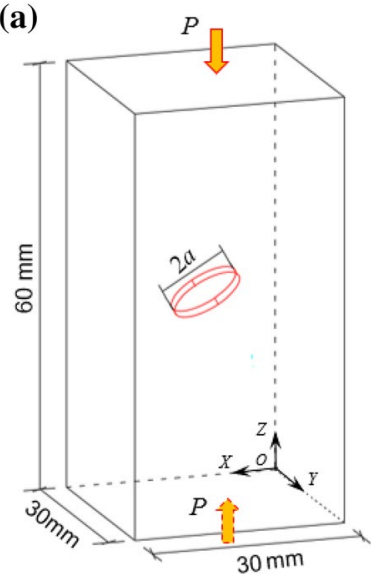

(b)

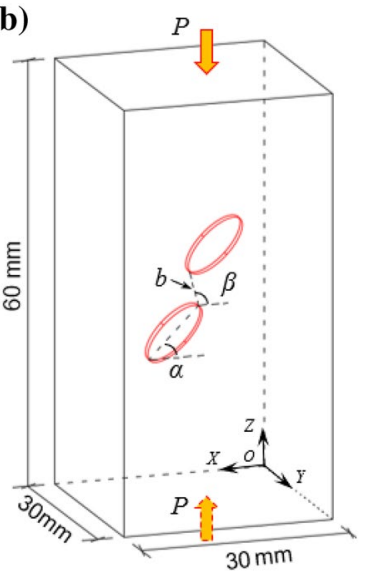

Fig. 1 Geometry of: a Single flaw; and $\mathbf{b}$ double flaws in 3DP samples. $\alpha$ and $\beta$ are inclination angle and bridge angle, $a$ and $b$ are the radius of flaw and bridge length between the two flaws, respectively. $\mathrm{O}$ is origin. The yellow arrows refer to the dynamic loading directions, and the red circles represent the pre-existing 3D embedded flaws. Notably, the dynamic loading direction has been rotated $90^{\circ}$ counterclockwise (color figure online)

in this study, the terms "flaw" and "crack" refer to the preexisting defects and the newly generated cracks (e.g., wing and secondary cracks) inside the sample, respectively, and "fracture" refers only to the crack evolution process.

\section{Experimental Setup}

\subsection{Sample Preparation}

Details of the sample preparation and 3DP are provided in our previous studies (Zhou et al. 2019; Zhu et al. 2018). Figure 1 presents the sample geometry, where the flaw angles $(\alpha)$ of the samples with one and two flaws are $30^{\circ}$ and $45^{\circ}$, respectively; for samples with two flaws, the bridge angle $(\beta)$ between the inner tips of the two flaws is $105^{\circ}$. Table 1 provides specific information on the 3D-printed samples, where samples S-1 and D-1 represent static and dynamic uniaxial compression tests conducted on 3D-printed samples containing a single flaw, respectively. The aperture of the flaws is $2 \mathrm{~mm}$. Notably, because one of the advantages of 3DP is its high repeatability in sample preparation and thus experimental results (Gell et al. 2019; Jiang and Zhao 2015; Jiang et al. 2016), only one sample was tested per geometry.

\subsection{Apparatus}

The dynamic tests were performed with a modified SHPB device ( $\mathrm{Li}$ et al. 2005; Liao et al. 2016). During testing, the cone-shaped striker impacted the input bar, generating a half-sine incident pulse (time duration of approximately

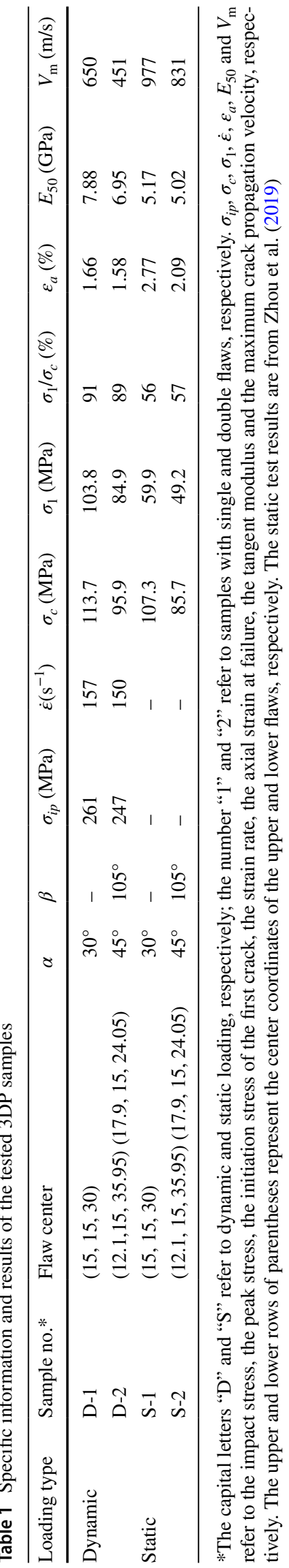


$250 \mu \mathrm{s})$ that propagated along the steel bars. When the incident wave $\varepsilon_{\mathrm{I}}(t)$ arrived at the bar-sample interface, it split into a reflected wave $\varepsilon_{\mathrm{R}}(t)$ and a transmitted wave $\varepsilon_{\mathrm{T}}(t)$. When the stresses at the sample sides were approximately equal, a stress balance was achieved within the sample. Then, according to the ISRM-suggested method (Zhou et al. 2012), the dynamic compressive stress $\sigma(t)$ and strain $\varepsilon(t)$ can be determined as

$\sigma(t)=\frac{A_{e} E_{e}}{2 A_{s}}\left[\varepsilon_{\mathrm{I}}(t)+\varepsilon_{\mathrm{R}}(t)-\varepsilon_{\mathrm{T}}(t)\right]$

$\varepsilon(t)=\frac{C_{e}}{L_{s}} \int_{0}^{t}\left[\varepsilon_{\mathrm{I}}(t)-\varepsilon_{\mathrm{R}}(t)-\varepsilon_{\mathrm{T}}(t)\right] d t$

where $A_{e}, C_{e}$, and $E_{e}$ are the cross-sectional area $\left(1963.5 \mathrm{~mm}^{2}\right)$, longitudinal wave velocity $(5400 \mathrm{~m} / \mathrm{s})$, and elastic modulus (240 GPa) of the steel bars, respectively. $A_{s}$ and $L_{s}$ refer to the cross-sectional area $\left(\mathrm{mm}^{2}\right)$ and length $(\mathrm{mm})$ of the sample, respectively.

In the SHPB tests, two FASTCAM SA1.1 high-speed cameras (HSCs) were utilized to monitor real-time volumetric fracturing in two orthogonal directions. The HSCs were automatically triggered by the input signal, and the frame rate and resolutions were 125,000 frames per second (fps) and $256 \times 128$ pixels, respectively. Accordingly, the time interval between the two adjacent high-speed images was $8 \mu$ s. Notably, as the HSC's storage space was $8 \mathrm{~GB}$, the recording time of the HSC was restricted to $0.56 \mathrm{~s}$ during the SHPB tests.

\section{Results}

\subsection{Mechanical Properties}

Figure 2 presents the dynamic stress-strain curves of the samples with one and two 3D embedded flaws. The results show that when the number of flaws increased from one to two, the dynamic compressive strength decreased from 113.7 to $95.9 \mathrm{MPa}$, a reduction of $15.7 \%$; the tangent modulus at half the peak stress decreased by $11.8 \%$; and the maximum axial strain at failure of the sample slightly reduced by $4.8 \%$. However, the shapes of the dynamic stress-strain curves of the single-flawed and double-flawed samples are similar, which indicates that the number of flaws may not affect the dynamic stress-strain behaviour of the samples.

\subsection{Volumetric Fracturing in 3D-printed Samples}

The images of the volumetric fracturing of the flawed samples are shown in Fig. 3. Regarding the sample containing

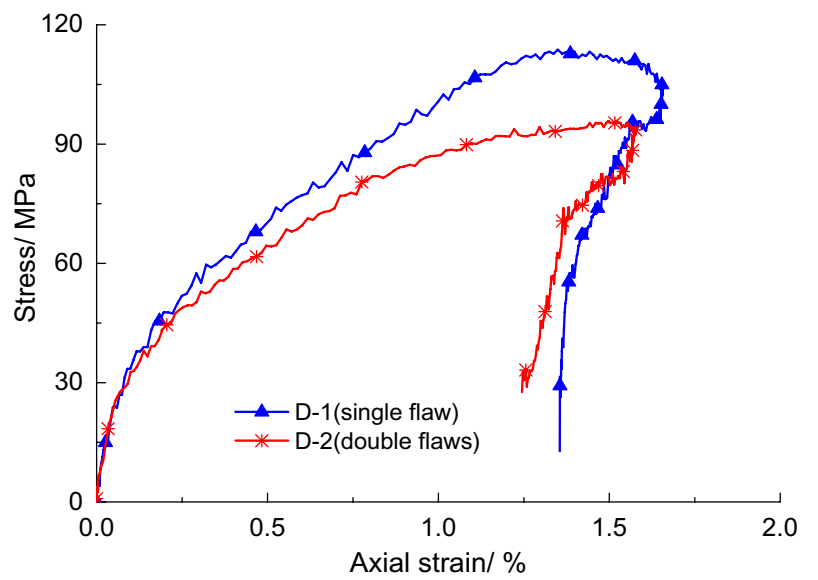

Fig. 2 Dynamic stress-strain curves of the 3DP samples containing single and double flaws

a single flaw, when the dynamic stress reached $91 \%$ of the peak stress (113.7 MPa), at a loading time of approximately $104 \mu$ s, symmetrical wing cracks almost simultaneously initiated at the flaw tips (Fig. 3a). With increasing load, the wing cracks slightly wrapped around the flaw boundary and synchronously propagated at a relatively steady rate towards the sample ends, eventually splitting the 3D-printed resin sample into strips, as shown in Fig. 3c.

For the double-flawed sample, two wing cracks almost simultaneously initiated at the inner tip of the upper flaw and outer tip of the lower flaw, respectively, when the dynamic stress reached approximately $90 \%$ of the peak stress (95.9 MPa) (see Fig. 3b). The extension and interaction of the wing cracks from inner tips of the flaws resulted in the coalescence of flaws (Fig. 3b). Subsequently, a wing crack initiated at the outer tip of the upper flaw when the loading time reached approximately $104 \mu \mathrm{s}$. Then, the wing cracks at the outer tips of the upper and lower flaws continuously extended along the dynamic impact direction towards the ends of the sample as the loading time increased to approximately $200 \mu \mathrm{s}$. However, propagation of the coalescent wing cracks at the inner tips of the flaws was constrained by the dominant evolution of the wing cracks at the outer tips of the flaws and could not expand farther (Fig. 3b). The continuous extension of wing cracks at the outer tips of the flaws finally resulted in the tensile failure of the sample (Fig. 3d). Figure 3 also shows that the fracturing and failure behaviour between the singleflawed and double-flawed samples are similar, except that crack coalescence occurs in the double-flawed sample. This similarity indicates that the number of flaws exerts an insignificant influence on the fracture and failure mode of the samples containing 3D embedded flaws. 


\subsection{Crack Propagation Velocity}

With the aid of an HSC, real-time fracturing can be monitored during testing; therefore, the crack propagation velocity $\left(V_{\mathrm{c}}\right)$ can be determined. Notably, $V_{\mathrm{c}}$ is an average velocity value within a time interval (i.e., $8 \mu \mathrm{s}$ ) and is defined as the ratio of the propagation length over the time interval between two high-speed images. Figure 4 illustrates crack propagation velocities in samples with single and double 3D embedded flaws subjected to dynamic compression. In general, the $V_{\mathrm{c}}$ of wing cracks tends towards a stable value, and the terminal speed is slightly lower than the initial speed. For example, the initial and terminal propagation speeds of the wing crack at the outer tip of the upper flaw in the double-flawed samples were approximately 350 and $319 \mathrm{~m} / \mathrm{s}$, respectively. However, the maximum $V_{\mathrm{c}}$ of the single-flawed sample $(650 \mathrm{~m} / \mathrm{s})$ was nearly $30 \%$ higher than that of the double-flawed sample $(451 \mathrm{~m} / \mathrm{s})$.

\section{Discussion}

\subsection{Comparison of the Mechanical Behaviour of 3D Flawed Samples Under Dynamic and Static Loading Conditions}

Table 1 lists the mechanical properties of the tested 3D-printed samples under static compression (Zhou et al. 2019) and dynamic compression. The mechanical properties are dependent on the loading conditions. For instance, from static compression to dynamic compression, the axial strain at failure decreased by $40.1 \%$ and $24.4 \%$ for samples containing one and two flaws, while the tangent modulus increased by $52.4 \%$ and $38.4 \%$, respectively. The strain rate effect on the mechanical properties of 3D-printed resin is believed to be associated with secondary molecular processes, which means that increasing the loading rate decreases the molecular mobility of polymer chains, thus stiffening the chains (Richeton et al. 2006). This mechanism is similar to the temperature effect on the compressive strength of polymers, where a very low environmental temperature strongly constrains the movement of polymer chains, yielding a higher compressive strength of polymers at temperatures below the glass transition temperature (Zhou and Zhu 2018).

In the SHPB tests, the impact of the number of flaws on the initiation stress $\left(\sigma_{1}\right)$ of the first crack to form in $3 \mathrm{D}$-printed resin samples is consistent with that on the peak stress $\left(\sigma_{C}\right)$, i.e., $\sigma_{1}$ decreases with an increasing number of flaws. However, the effect of the number of flaws on the ratio of $\sigma_{1} / \sigma_{C}$, which was approximately 0.9 for the flawed samples in the dynamic tests, is negligible. This is similar to the findings in static compression tests, where $\sigma_{1} / \sigma_{C}$ also seemed to be unaffected by the number of flaws, although $\sigma_{1}$ in samples containing two 3D embedded flaws is lower than that in samples with a single flaw (Zhou et al. 2019). This lack of variability is possibly because $\sigma_{1} / \sigma_{C}$ is an intrinsic property of a rock material, which may be unaffected by the sample geometry and boundary conditions (Bieniawski 1967; Diederichs et al. 2004; Xu et al. 2018). In addition, $\sigma_{1}$ in the dynamic tests increased by approximately $73 \%$ and $80 \%$ for samples with single and double flaws, respectively, compared with the results of the static tests, which means that a strong strain rate effect on $\sigma_{1}$ exists. This effect is consistent with the results found in the numerical study of the effect of loading rate on crack initiation stress, despite the difference in the magnitude of increase (Zhang and Wong 2013). The reason why $\sigma_{1}$ is higher under dynamic loading than under static loading is mainly because the crack initiation toughness is rate dependent and increases with the strain/loading rate (Jajam et al. 2013; Zhou et al. 2018b).

\subsection{Comparison of the Fracturing Behaviour of 3D Flawed Samples Under Dynamic and Static Loading Conditions}

Wing crack growth in samples with $3 \mathrm{D}$ embedded flaws is significantly different under dynamic and static loading conditions, as shown in Fig. 5. Under dynamic compression, wing cracks rapidly propagated and continuously extended to the ends of the sample, finally resulting in a splitting failure of the sample, whereas under static compression, wing cracks intermittently formed but could extend only a limited distance, and the final failure was caused by secondary cracks (the secondary cracks initiated later than the wing cracks). This difference possibly arises because under dynamic loading, after crack initiation, the stress intensity factor (SIF) remains approximately constant for a certain time, which drives wing cracks to grow continuously until sample failure (Li et al. 2000), whereas in the static compression test, the wrapping of wing cracks around the flaw edges restricts the wing cracks from propagating a long distance (Dyskin et al. 2003).

In addition, unlike under static compression (Fu et al. 2016; Zhou et al. 2019), under dynamic loading, anti-wing cracks (see Fig. 5b) did not initiate in the flawed samples. This phenomenon may be attributed to stress wave propagation altering the stress field around the 3D flaw tips where anti-wing cracks could initiate under static compression. This mechanism is similar to the mechanism controlling the initiation of shear cracks before tensile cracks from the 2D flaw tips under dynamic loading ( $\mathrm{Li}$ et al. 2017; Li and Wong 2012). Under dynamic loading, the arrival of the stress wave generates compressive stress where tensile cracks often initiate under static loading, temporarily constraining the development of tensile cracks (Li and Wong 2012). 

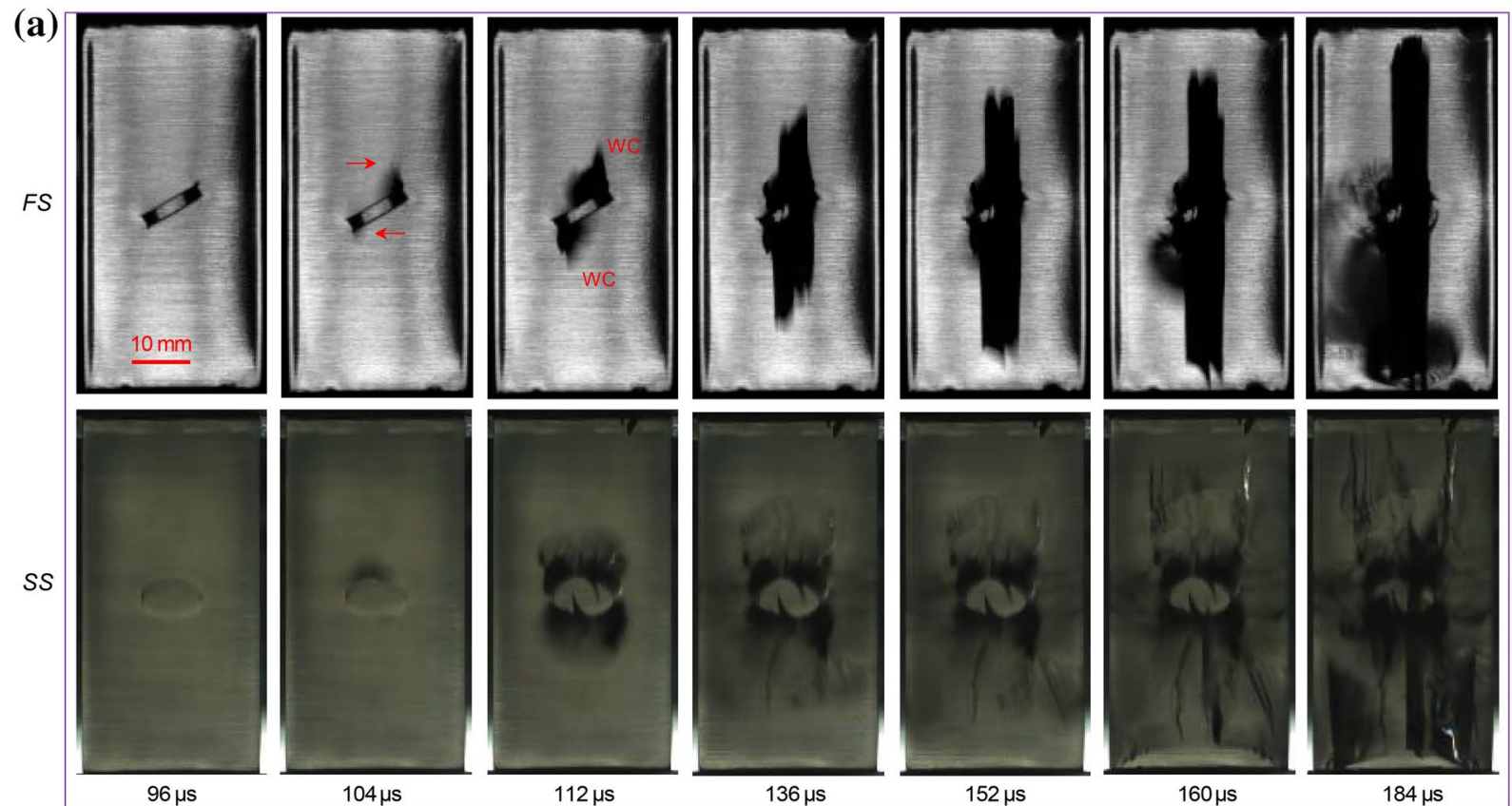

(b)
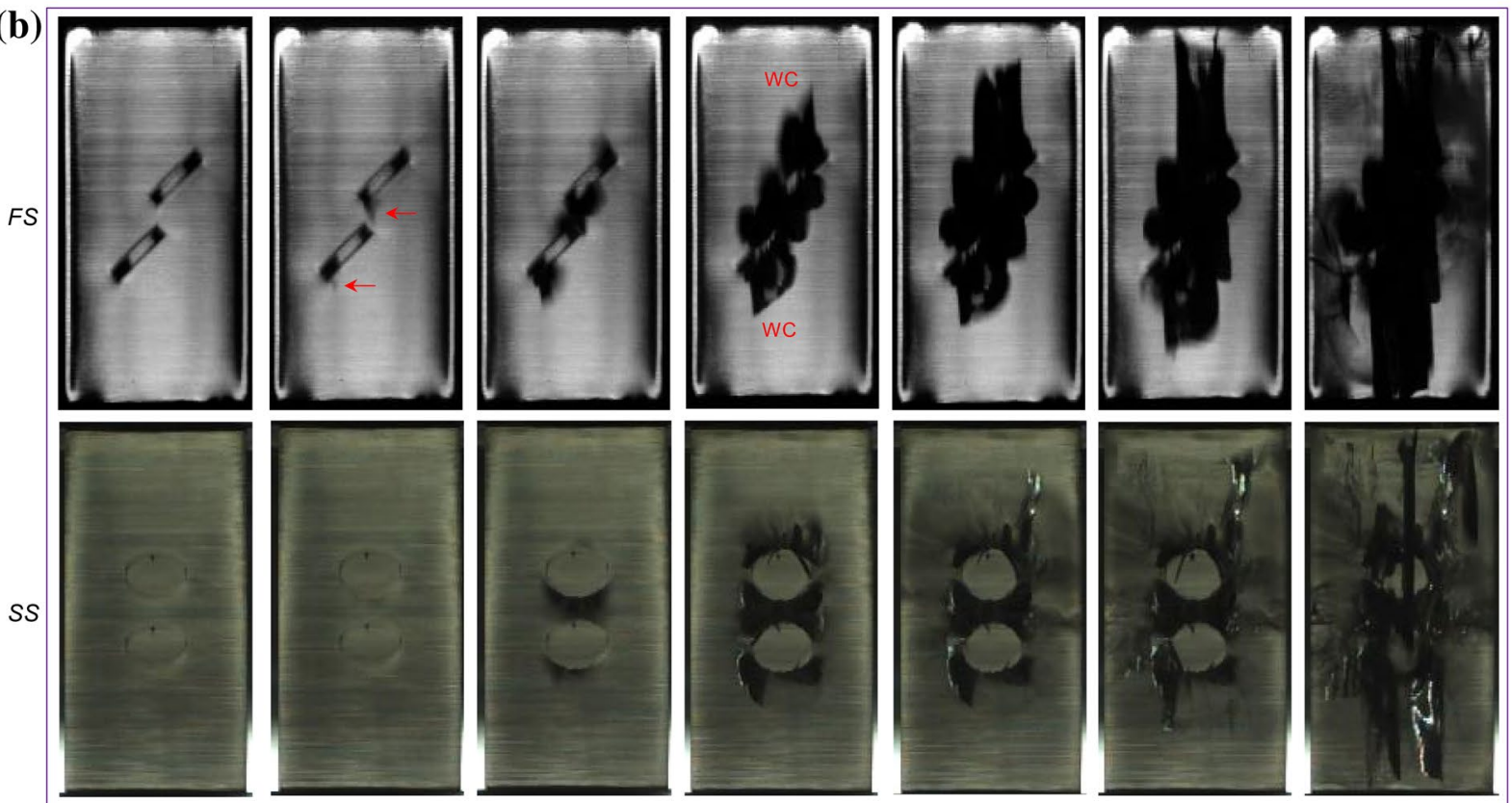

(c)
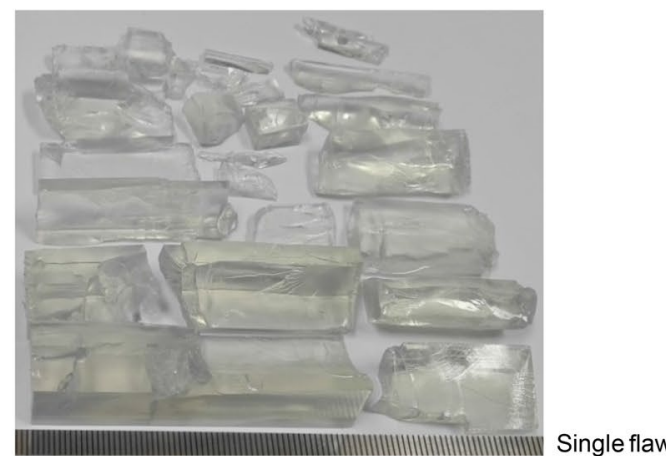

(d)

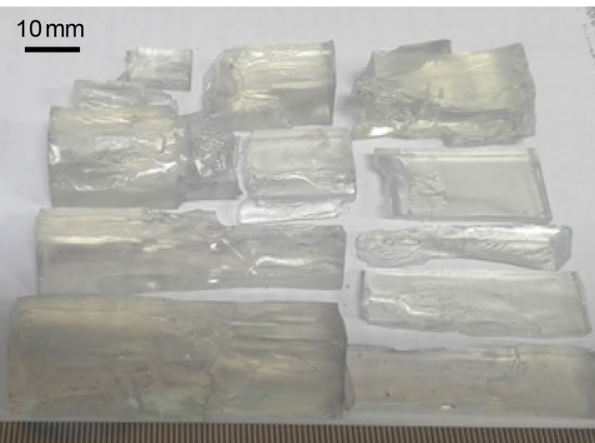


4Fig. 3 Volumetric fracturing of the flawed samples: a and b Progressive fracturing of the sample with single and double 3D embedded flaws, respectively; $\mathbf{c}$ and $\mathbf{d}$ failure fragments after dynamic compression tests. FS and SS represent photographing from front and side surfaces of the resin sample, respectively. The time marked in (a) and (b) is the absolute time from the start of dynamic loading. WC indicates wing cracks. Red arrows indicate the newly generated wing cracks (color figure online)

Moreover, the wing crack propagation speed approached a relatively stable value under dynamic loading conditions, whereas under static compression, $V_{\mathrm{c}}$ of the secondary cracks quickly decreased with increasing propagation time, as shown in Fig. 6. The difference in the decrease in velocity between the dynamic and static tests is probably because the dynamic stress could be roughly maintained at the peak stress level during the entire crack propagation process, even within a certain period during the unloading process in the SHPB tests, whereas under static loading conditions, due to the rapid unloading of the axial stress caused by the burstlike failure of the sample, the peak stress cannot be maintained after initiation of the secondary cracks (Gao et al. 2015; Li et al. 2017). However, the maximum $V_{\mathrm{c}}(650 \mathrm{~m} / \mathrm{s})$ in the SHPB tests was lower than that in the static compression tests $(977 \mathrm{~m} / \mathrm{s})$. The difference may be attributed to the discrepancy between the SIFs of samples under dynamic and static compression conditions. Take the sample containing a single $3 \mathrm{D}$ embedded flaw as an example. In the SHPB and static compression tests, the stresses applied to the sample were $102.8 \mathrm{MPa}$ (approximately $90 \%$ of the peak stress) and 107.3 MPa, respectively, when the wing cracks and secondary cracks initiated at the flaw tips or around the flaw edges. As the SIF is related to the stress around/ahead of the flaw/crack tips (Benz and Sander 2014; Rossmanith 1983), it is therefore inferred that the higher loading stress under static compression may result in greater SIFs around

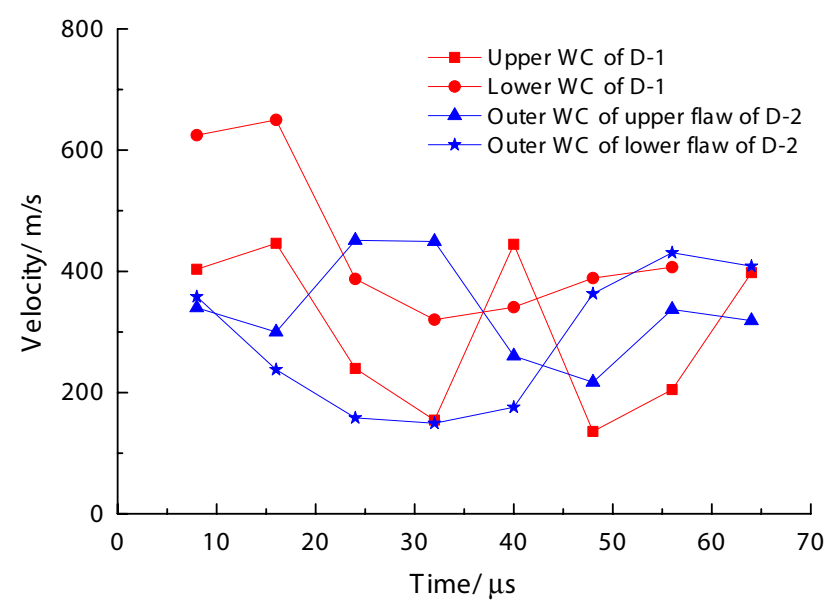

Fig. 4 Crack propagation velocities in dynamic compression tests the flaw/crack tips than those resulting from the SHPB tests. Moreover, according to Charles' law, $V_{\mathrm{c}}$ is dependent on SIF, i.e., $V_{\mathrm{c}}=a \cdot b^{n}$, in which $a$ is constant, $b$ is the SIF, and $n$ is the stress corrosion index whose range is 20-60 for geomaterials (Atkinson and Meredith 1987a, b; Main et al. 1989). Consequently, the greater SIFs in as specimen under static loading may result in more rapid crack propagation.

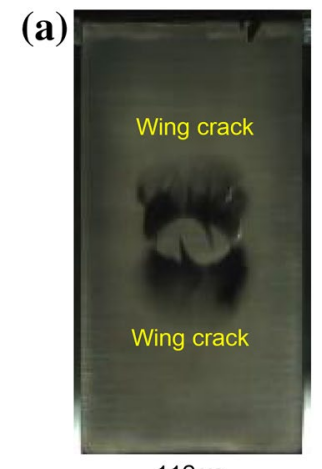

$112 \mu s$

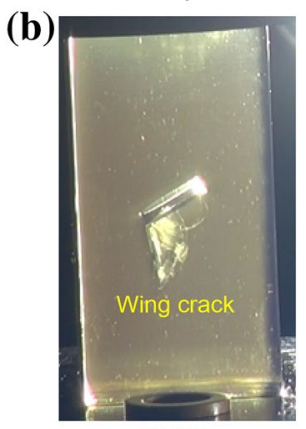

$60 \mathrm{MPa}$

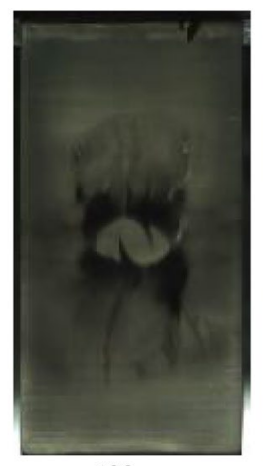

$136 \mu \mathrm{s}$

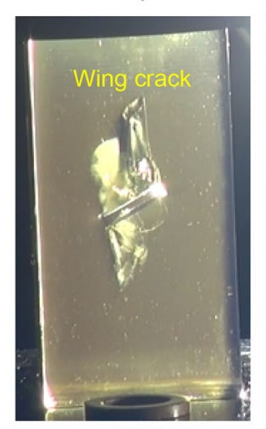

$73 \mathrm{MPa}$

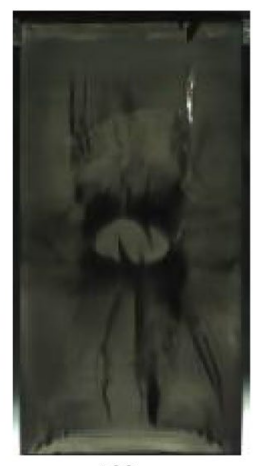

$160 \mu s$

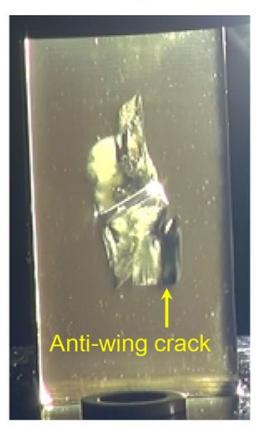

$80 \mathrm{MPa}$
Fig. 5 Wing crack growth in: a Dynamic test; and b static test. The crack growth in static test was modified after Zhou et al. (2019). The time marked in (a) is the absolute time from the start of dynamic loading. The stress marked in (b) is the initiation stress of the wing and anti-wing cracks during static compression

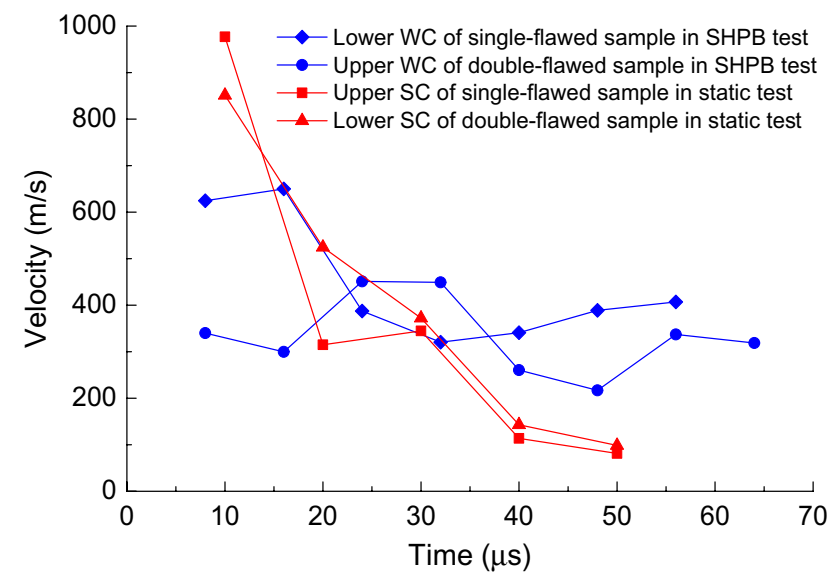

Fig. 6 Crack propagation velocities in dynamic and static compression tests. The crack propagation velocity data in static test is modified after Zhou et al. (2019). SC refers to secondary crack 
Fig. 7 Crack patterns in samples with 2D and 3D flaws under dynamic loading. a Marble sample with a single 2D flaw (Zou and Wong 2014); b 3DP resin sample with a single 3D embedded flaw
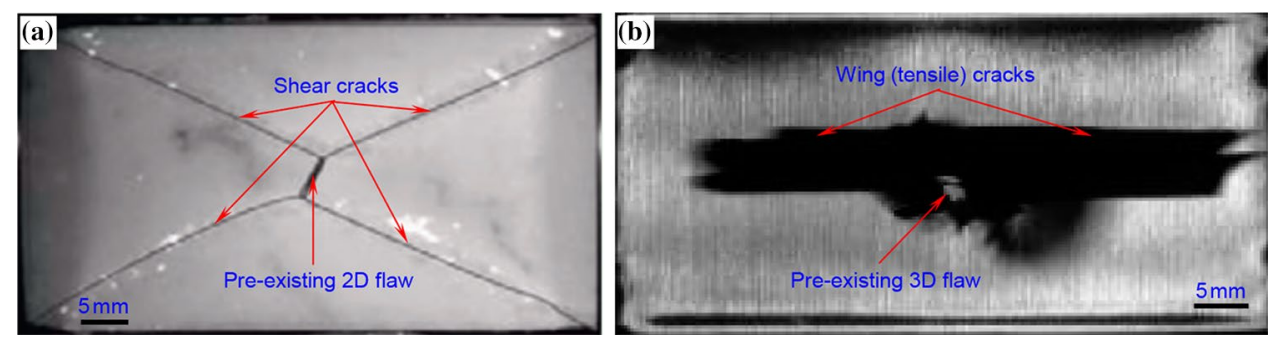

\subsection{Comparison of the Fracturing Behaviour of 2D and 3D Embedded Flaws Under Dynamic Loading Conditions}

Under dynamic compression, the volumetric fracturing behaviour among samples with single 2D and 3D embedded flaws is distinct. For a sample with a 2D flaw, the dominant shear crack results in the final failure with an X-shaped pattern, as shown in Fig. 7a (Zou and Wong 2014; Li et al. 2017). Li and Wong (2012) reported that high compressive stresses at 2D flaw tips lead to the rapid initiation and propagation of shear cracks. In contrast, wing cracks initiate at 3D embedded flaw tips and continuously extend towards the sample ends (Fig. 7b). This failure mode may be due to the sliding of flaw surfaces, which resembles that observed during 2D crack propagation under static compression (NematNasser and Horii 1982).

\section{Conclusions}

Dynamic impact tests were conducted on 3D-printed resin samples with 3D embedded flaws using a SHPB device. The mechanical and fracturing behaviour of the flawed-samples were investigated. The difference between the mechanical and volumetric fracturing behaviour of a 3D embedded flaw under static and dynamic loading conditions and between volumetric fracturing and $2 \mathrm{D}$ fracturing behaviour under dynamic loading conditions were determined. The main conclusions of this paper are summarized as follows.

(1) The loading type influences the mechanical properties of samples containing 3D embedded flaws. From static compression to dynamic compression, $\sigma_{C}$ increases by approximately $8 \%$, and the maximum axial strain decreases by $40.1 \%$ and $24.4 \%$ for samples with one and two 3D embedded flaws, respectively. The Young's modulus, $\sigma_{1}$ and $\sigma_{1} / \sigma_{C}$ significantly increase when the loading type changes from static to dynamic.

(2) The number of flaws has a very limited effect on the ratio of $\sigma_{1} / \sigma_{C}$ and the volumetric fracturing behaviour of the flawed samples. The ratio of $\sigma_{1} / \sigma_{C}$ is approximately $90 \%$ for the flawed samples under dynamic loading. The propagation behaviour of wing cracks, the failure mode and fragment geometry after failure are almost identical between the samples with one and two 3D embedded flaws.

(3) The volumetric fracturing of $3 \mathrm{D}$ embedded flaws is strain rate dependent. Under dynamic compression, wing cracks can continuously extend toward the sample ends, resulting in splitting failure of the sample, whereas wing cracks could only intermittently grow a limited distance under static compression. The crack propagation speed approaches a stable value under dynamic loading, but the peak crack propagation velocity in the SHPB tests is lower than that in the static compression tests.

(4) Under dynamic loading, the fracturing of samples with 3D embedded flaws is distinct from that of the samples with 2D flaws. Wing cracks initiation at the 3D flaw tips lead to splitting failure of the sample, while the dominant shear cracks initiating at 2D flaw tips result in shear failure of the sample.

Although the preliminary findings of this study could facilitate a better understanding of rock failure behaviour, the resin-based artificial rock samples cannot completely reflect the mechanical and fracturing behaviour of hard and brittle rocks due to the limitations (e.g. low Young's modulus and almost no porosity) of the 3D-printed resin material. Therefore, further improvements, e.g., enhancing the 3D-printed resin's elastic modulus and brittleness or implanting the internal micro- and macro-cracks geometries of natural rock into 3D-printed resin-based samples, are needed so that the properties of the 3D-printed resin approach those of actual rocks. In addition, further efforts are needed to more precisely and quantitatively characterize the 3D stress field around pre-existing flaws and the progressive fracture process subjected to different loading conditions by means of, for example, the digital image correlation and photoelastic methods.

Acknowledgements We thank Y. Ju from China University of Mining and Technology Beijing for the constructive comments and suggestions to the paper; we thank W.F. Wong and C.M. Wong from Industrial Centre of the Hong Kong Polytechnic University for their support in 3DP sample preparation; we also thank X.B. Li at Central South 
University for providing some of the testing apparatuses. This research is financially supported by the National Key R\&D Program of China (No. 2018YFC0407002), the Hong Kong Research Grant Council (No. 25201814) and the National Natural Science Foundation of China (No. 41402241).

Open Access This article is licensed under a Creative Commons Attribution 4.0 International License, which permits use, sharing, adaptation, distribution and reproduction in any medium or format, as long as you give appropriate credit to the original author(s) and the source, provide a link to the Creative Commons licence, and indicate if changes were made. The images or other third party material in this article are included in the article's Creative Commons licence, unless indicated otherwise in a credit line to the material. If material is not included in the article's Creative Commons licence and your intended use is not permitted by statutory regulation or exceeds the permitted use, you will need to obtain permission directly from the copyright holder. To view a copy of this licence, visit http://creativecommons.org/licenses/by/4.0/.

\section{Appendix}

\section{Supplementary videos}

Four supplementary videos taken by the HSCs are supplied for better understanding 3D internal crack growth under dynamic compression. Notably, all of the videos are played at three frames per second and can be viewed through the Nature Springer suggested website: https://doi.org/10.6084/ m9.figshare.7525001.v1.

\section{References}

Adams M, Sines G (1978) Crack extension from flaws in a brittle material subjected to compression. Tectonophysics 49:97-118

Atkinson BK, Meredith PG (1987a) The theory of subcritical crack growth with applications to minerals and rocks. Fract Mech Rock 2:111-166

Atkinson BK, Meredith PG (1987b) Experimental fracture mechanics data for rocks and minerals. Fract Mech Rock 28:477-525

Benz C, Sander M (2014) Fatigue crack growth testing at negative stress ratios: discussion on the comparability of testing results. Fatigue Fract Eng Mater Struct 37(1):62-71

Bieniawski ZT (1967) Mechanism of brittle fracture of rock: part II-experimental studies. Int J Rock Mech Min Sci 4(4):407-423

Bobet A, Einstein HH (1998) Fracture coalescence in rock-type materials under uniaxial and biaxial compression. Int J Rock Mech Min Sci 35:863-888

Cannon NP, Schulson EM, Smith TR, Frost H (1990) Wing cracks and brittle compressive fracture. Acta Mater 38:1955-1962

Deng XF, Chen SG, Zhu JB, Zhao ZY, Zhou YX, Zhao J (2015) UDEC-AUTODYN hybrid modeling of a large-scale underground explosion test. Rock Mech Rock Eng 48:737-747

Diederichs MS, Kaiser PK, Eberhardt E (2004) Damage initiation and propagation in hard rock during tunnelling and the influence of near-face stress rotation. Int J Rock Mech Min Sci 41(5):785-812

Dyskin AV, Jewell RJ, Joer H, Sahouryeh E, Ustinov KB (1994) Experiments on 3-D crack growth in uniaxial compression. Int J Fract 65(4):R77-R83
Dyskin AV, Sahouryeh E, Jewell RJ, Joer H, Ustinov KB (2003) Influence of shape and locations of initial 3-D cracks on their growth in uniaxial compression. Eng Fract Mech 70:2115-2136

Feng XT, Ding W, Zhang D (2009) Multi-crack interaction in limestone subject to stress and flow of chemical solutions. Int J Rock Mech Min Sci 46(1):159-171

Fu JW, Chen K, Zhu WS, Zhang XZ, Li XJ (2016) Progressive failure of new modelling material with a single internal crack under biaxial compression and the 3-D numerical simulation. Eng Fract Mech 165:140-152

Gale JF, Reed RM, Holder J (2007) Natural fractures in the Barnett Shale and their importance for hydraulic fracture treatments. AAPG Bull 91:603-622

Gao G, Yao W, Xia K, Li Z (2015) Investigation of the rate dependence of fracture propagation in rocks using digital image correlation (DIC) method. Eng Fract Mech 138:146-155

Gell EM, Walley SM, Braithwaite CH (2019) Review of the validity of the use of artificial samples for characterizing the mechanical properties of rocks. Rock Mech Rock Eng 52(9):2949-2961

Germanovich LN, Salganik RL, Dyskin AV, Lee KK (1994) Mechanisms of brittle fracture of rock with pre-existing cracks in compression. Pure Appl Geophys 143:117-149

Jajam KC, Bird SA, Auad ML, Tippur HV (2013) Tensile, fracture and impact behaviour of transparent Interpenetrating Polymer Networks with polyurethane-poly (methyl methacrylate). Polym Test 32(5):889-900

Jiang C, Zhao GF (2015) A preliminary study of 3D printing on rock mechanics. Rock Mech Rock Eng 48(3):1041-1050

Jiang Q, Feng X, Gong Y, Song L, Ran S, Cui J (2016) Reverse modelling of natural rock joints using 3D scanning and 3D printing. Comput Geotech 73:210-220

Li HQ, Wong LNY (2012) Influence of flaw inclination angle and loading condition on crack initiation and propagation. Int J Solids Struct 49(18):2482-2499

Li HB, Zhao J, Li TJ (2000) Micromechanical modelling of the mechanical properties of a granite under dynamic uniaxial compressive loads. Int J Rock Mech Min Sci 37(6):923-935

Li X, Lok T, Zhao J (2005) Dynamic characteristics of granite subjected to intermediate loading rate. Rock Mech Rock Eng 38(1):21-39

Li XB, Zhou T, Li DY, Wang ZW (2016) Experimental and numerical investigations on feasibility and validity of prismatic rock sample in SHPB. Shock Vib. https://doi.org/10.1155/2016/7198980

Li X, Zhou T, Li D (2017) Dynamic strength and fracturing behaviour of single-flawed prismatic marble samples under impact loading with a split-Hopkinson pressure bar. Rock Mech Rock Eng 50(1):29-44

Liang ZZ, Xing H, Wang SY, Williams DJ, Tang CA (2012) A threedimensional numerical investigation of the fracture of rock samples containing a pre-existing surface flaw. Comput Geotech 45:19-33

Liao ZY, Zhu JB, Xia KW, Tang CA (2016) Determination of dynamic compressive and tensile behavior of rocks from numerical tests of split Hopkinson pressure and tension bars. Rock Mech Rock Eng 49:3917-3934

Liu HY, Kou SQ, Lindqvist PA, Tang CA (2004) Numerical studies on the failure process and associated microseismicity in rock under triaxial compression. Tectonophysics 384(1):149-174

Main IG, Meredith PG, Jones C (1989) A reinterpretation of the precursory seismic b-value anomaly from fracture mechanics. Geophys J Int 96(1):131-138

Nemat-Nasser S, Horii H (1982) Compression-induced nonplanar crack extension with application to splitting, exfoliation, and rockburst. J Geophys Res 87:6805-6821 
Peng S, Johnson AM (1972) Crack growth and faulting in cylindrical samples of Chelmsford granite. Int J Rock Mech Min Sci Geomech Abstr 9:37-86

Richeton J, Ahzi S, Vecchio KS, Jiang FC, Adharapurapu RR (2006) Influence of temperature and strain rate on the mechanical behaviour of three amorphous polymers: characterization and modeling of the compressive yield stress. Int J Solids Struct 43:2318-2335

Rossmanith HP (1983) Dynamic crack analysis and the interaction between cracks and waves. Rock fracture mechanics. Springer, Vienna, pp 271-300

Wong LNY, Einstein HH (2009) Systematic evaluation of cracking behaviour in samples containing single flaws under uniaxial compression. Int J Rock Mech Min Sci 46:239-249

Wong RHC, Chau KT, Tang CA, Lin P (2001) Analysis of crack coalescence in rock-like materials containing three flaws-part I: experimental approach. Int J Rock Mech Min Sci 38(7):909-924

Wong RHC, Law CM, Chau KT, Zhu WS (2004) Crack propagation from 3-D surface fractures in PMMA and marble samples under uniaxial compression. Int J Rock Mech Min Sci 41:37-42

Xie HP, Gao F, Ju Y et al (2016) Novel idea of the theory and application of 3D volume fracturing for stimulation of shale gas reservoirs. Chin Sci Bull 61:36-46 (in Chinese)

Xu X, Wu S, Jin A, Gao Y (2018) Review of the relationships between crack initiation stress, Mode I fracture toughness and tensile strength of geo-materials. Int J Geomech 18(10):04018136

Yang SQ, Dai YH, Han LJ, Jin ZQ (2009) Experimental study on mechanical behaviour of brittle marble samples containing different flaws under uniaxial compression. Eng Fract Mech 76(12):1833-1845

Yim CS, Chopra AK, Penzien J (1980) Rocking response of rigid blocks to earthquakes. Earthq Eng Struct Dyn 8:565-587

Yin P, Wong RHC, Chau KT (2014) Coalescence of two parallel pre-existing surface cracks in granite. Int J Rock Mech Min Sci 68:66-84

Zhang XP, Wong LNY (2013) Loading rate effects on cracking behaviour of flaw-contained samples under uniaxial compression. Int $\mathbf{J}$ Fract 180(1):93-110
Zhang JZ, Zhou XP, Zhu JY, Xian C, Wang YT (2018) Quasi-static fracturing in double-flawed samples under uniaxial loading: the role of strain rate. Int J Fract 211(1-2):75-102

Zhou T, Zhu JB (2018) Identification of a suitable 3D printing material for mimicking brittle and hard rocks and its brittleness enhancements. Rock Mech Rock Eng 51:765-777

Zhou YX, Xia K, Li XB, Li HB, Ma GW, Zhao J et al (2012) Suggested methods for determining the dynamic strength parameters and mode-I fracture toughness of rock materials. Int J Rock Mech Min Sci 49:105-112

Zhou L, Zhu Z, Qiu H, Zhang X, Lang L (2018a) Study of the effect of loading rates on crack propagation velocity and rock fracture toughness using cracked tunnel samples. Int J Rock Mech Min Sci 112:25-34

Zhou XP, Zhang JZ, Wong LNY (2018b) Experimental study on the growth, coalescence and wrapping behaviour of 3D crossembedded flaws under uniaxial compression. Rock Mech Rock Eng 51(5):1379-1400

Zhou T, Zhu JB, Ju Y, Xie HP (2019) Volumetric fracturing behaviour of $3 \mathrm{D}$ printed artificial rocks containing single and double 3D internal flaws under static uniaxial compression. Eng Fract Mech 205:190-204

Zhu JB, Zhou T, Liao ZY, Sun L, Li XB, Chen R (2018) Replication of internal defects and investigation of mechanical and fracture behaviour of rock using 3D printing and 3D numerical methods in combination with X-ray computerized tomography. Int J Rock Mech Min Sci 106:198-212

Zou CJ, Wong LNY (2014) Experimental studies on cracking processes and failure in marble under dynamic loading. Eng Geol 173:19-31

Publisher's Note Springer Nature remains neutral with regard to jurisdictional claims in published maps and institutional affiliations. 